\title{
INTERLAMINAR TOUGHENING OF RESIN TRANSFER MOLDED LAMINATES BY ELECTROSPUN POLYCAPROLACTONE STRUCTURES: EFFECT OF THE INTERLEAVE MORPHOLOGY
}

\author{
Timo Meireman ${ }^{1 *}$, Sam van der Heijden ${ }^{1}$, Lode Daelemans ${ }^{1}$, Ives De Baere ${ }^{2}$, Hubert Rahier ${ }^{3}$, Wim Van \\ Paepegem $^{2}$, Karen De Clerck ${ }^{1}$ \\ ${ }^{1}$ Department of Textiles, Ghent University, Zwijnaarde, Belgium \\ ${ }^{2}$ Department of Materials Science and Engineering, Ghent University, Zwijnaarde, Belgium \\ ${ }^{3}$ Department of Materials and Chemistry, Vrije Universiteit Brussel, Brussels Belgium \\ ${ }^{(*)}$ Email: timo.meireman@ugent.be
}

\begin{abstract}
Previous work has shown that electrospun nanofibers can significantly improve the interlaminar fracture toughness of fiber reinforced composites. In this work the effect of the morphology of the toughening polymer is analysed by incorporating five different polycaprolactone (PCL) structures (nanofibers, microfibers, microspheres, dense films and PCL spray coated glass fibres) in the interlaminar regions (van der Heijden, 2016). The mode I and mode II interlaminar fracture toughness were evaluated. Analysing the fracture behaviour of the PCL toughened laminates ensures a better insight in the micromechanical mechanisms behind the observed interlaminar fracture toughness and results in guidelines on the optimal interleave morphology.
\end{abstract}

Keywords: nano-structures, resin transfer moulding (RTM), delamination

\section{INTRODUCTION}

Delamination and brittle matrix fracture have long been a problem of fiber reinforced composites. The use of electrospun nanofibers has been proposed to toughen composites and prevent delaminations (Kim, 1999). Such nanofibers can easily be placed between two reinforcing plies prior to composite production and result in a finely distributed second phase in the epoxy. Hence, there is no need to disperse them into the resin. With other toughening techniques like toughening with phase separations, the final phase separated morphology has a major influence on the fracture toughness (Hodgkin, 1998). As such also the morphology of the electrospun structure may affect the fracture toughness of nanofiber toughened laminates.

In the present work we investigate the effect of interleaving different electrospun PCL structures (nanofibers, microfibers, microspheres, films and spray coated PCL ) into the resin transfer molded glass epoxy laminates to increase their fracture toughness. This is evaluated in Mode I and Mode II. The study of PCL is especially relevant since some of the highest increases in interlaminar toughness have been obtained using PCL nanofibers (Daelemans, 2014).

\section{RESULTS AND CONCLUSIONS}

The PCL structures used for composite toughening are shown in figure 1 . The effects on the toughness when interleaving these morphologies in composites is shown in figure 2. A significant increase in the mode II fracture toughness requires porous interleave structures. These structures have an intense fine distribution of PCL phases in a surrounding epoxy phase allowing for the PCL to strain significantly when the epoxy surrounding is cracked. The use of 
highly porous PCL nanofibers gave the best result. The non-porous structures could not increase the mode II fracture toughness, but did allow for an important increase in Mode I fracture toughness. This is however combined with an expected detrimental effect on the overall mechanical properties of the composite such as the shear strength, bending stiffness and creep resistance of the laminate. In addition, the non-porous structures obstruct optimal infusion and are thus not suitable. To improve the interlaminar fracture toughness in both Mode I and Mode II without adverse effects, porous PCL structures are much more suitable compared to PCL films or spray coated fibers. Nanofiber interleaving structures show the best performance.
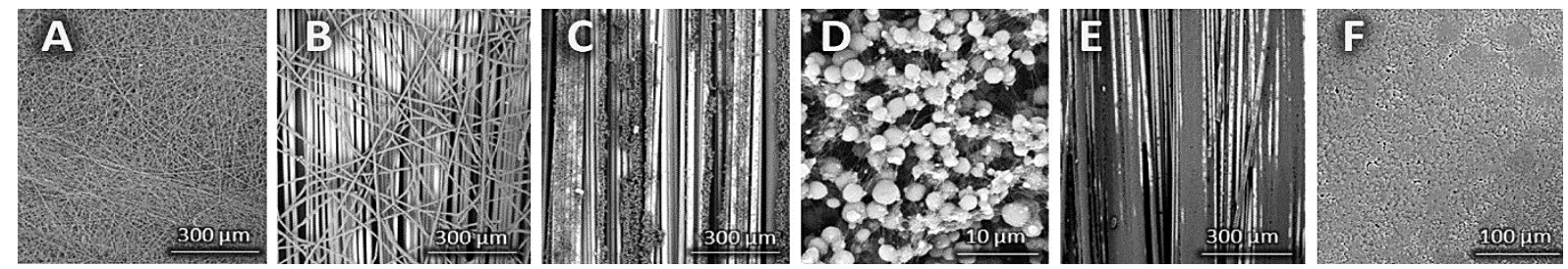

Fig. 1 - SEM images of different electrospun PCL structures: A, nanofibers $370 \mathrm{~nm}$; B, microfibers $8.35 \mu \mathrm{m} ; \mathrm{C}$ and $\mathrm{D}$, microspheres $1.8 \mu \mathrm{m}$; E, spray-coated glass fibers; F, film.
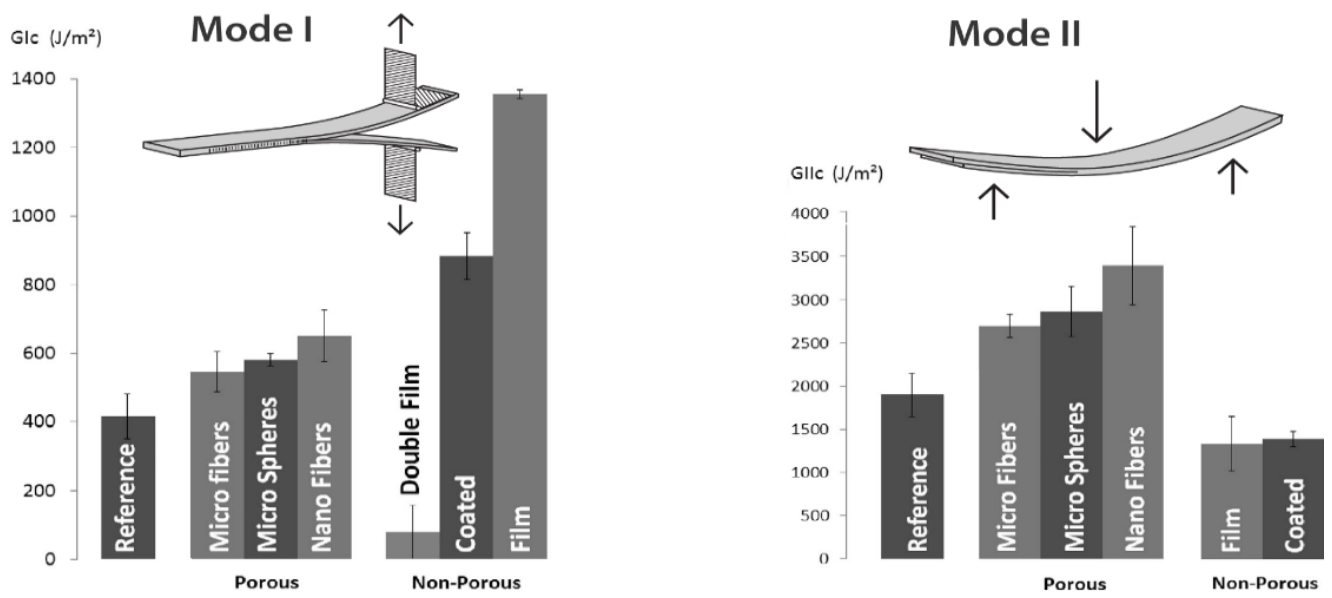

Fig. 2 - Mode I \& II fracture toughness of composites interleaved with different electrospun morphologies.

\section{ACKNOWLEDGMENTS}

Funding: This work was supported by The Agency for Innovation by Science and Technology of Flanders (IWT) [121156, 141344]; The UGent BOF project [13/24J/020].

\section{REFERENCES}

Daelemans L., Van der Heijden S, De Baere I., Rahier H., Van Paepegem W, De Clerck K. Damage-Resistant Composites Using Electrospun Nanofibers: A Multiscale Analysis of the Toughening Mechanisms. Applied Materials \& Interfaces, 2016, 18, p. 11806-11818.

Hodgkin J.H., Simon G.P., Varley R.J., Thermoplastic toughening of epoxy resins: a critical review. Polymer Advanced Technology, 1998, 9, p. 3-10.

Kim J.S., Reneker D.H., Mechanical properties of composites using ultrafine electrospun fibers. Polymer Composites, 1999, 20, p. 124-131.

Van der Heijden S., Daelemans L. Meireman T., De Baere I., Rahier H., Van Paepegem W, De Clerck K. Interlaminar toughening of resin transfer molded laminates by electrospun polycaprolactone structures: Effect of the interleave morphology. Composites Science and Technology, 2016, 136, p. 10-17 